\title{
Núcleo Maria da Penha: Desafios no Enfrentamento à Violência Contra a Mulher
}

\author{
Maria da Penha Nucleus: Challenges to Cope with Violence Against Women \\ Núcleo Maria da Penha: Desafíos en el Enfrentamiento a la Violencia Contra la Mujer
}

\author{
Katia Alexsandra dos Santos \\ Universidade Estadual do Centro-Oeste do Paraná \\ E-mail: kalexsandra@yahoo.com.br \\ Bianca Carolline Oconoski Zarpellon \\ Universidade Estadual do Centro-Oeste do Paraná \\ E-mail: bizarpellon@gmail.com
}

\section{Resumo}

O presente trabalho pretende apresentar as ações desenvolvidas pelo projeto de extensão Núcleo Maria da PenhaNUMAPE, da Universidade Estadual do Centro-Oeste, em Irati-PR. Trata-se de um projeto que se propõe a realizar atendimento psicológico e acompanhamento de mulheres com vistas ao enfrentamento das situações de violência. As ações têm se pautado em um eixo preventivo, com proposições de campanhas, palestras e formações sobre a temática; e em um eixo curativo, por meio do atendimento de mulheres que já passaram por situações de violência. O trabalho aponta alcances e limitações de um projeto que se coloca na relação com os desafios da tentativa de implementação de uma Rede de Enfrentamento à violência contra a mulher em um município de pequeno porte da região centro-sul do Paraná.

Palavras-chave: violência contra a mulher, atendimento psicológico, serviços sociais, gênero.

\section{Abstract}

This paper presents the activities developed by the project 'Maria da Penha' Nucleus (NUMAPE), maintained and supported by the Universidade Estadual do Centro-Oeste, in Irati, PR, Brazil. The project offers psychological assistance and follow-up procedures to women facing violence situations. The activities have been focusedon prevention, featuring campaigns, lectures and training on the theme, and on healing, offering assistance to women who have already experienced violence situations. This paper pinpoints achievements and limitations of a project which tries to implement a Network for facing violence against women in a small municipality in the central-southern region of the state of Paraná, Brazil.

Keywords: violence against women, psychological support, social services, gender.

\section{Resumen}

El trabajo presenta las acciones del proyecto de extensión Núcleo Maria da Penha-NUMAPE, de la Universidade Estadual do Centro-Oeste, en la ciudad de Irati-PR. Se trata de un proyecto que se propone a ofrecer atención psicológica y acompañamiento de mujeres, con proposiciones al enfrentamiento de las situaciones de violencia. Las acciones se han basado en un eje preventivo, con proposiciones de campañas, charlas y formaciones sobre la temática; y un eje curativo, a través de la atención de mujeres que ya pasaron por situación de violencia. El trabajo muestra alcances y limitaciones de un proyecto que se plantea en la relación con los desafíos del intento de implementación de una Red de Enfrentamiento a la violencia contra la mujer en una ciudad de pequeño porte de la región centro-sur de Paraná.

Palabras-clave: violencia contra la mujer, atención psicológica, servicios sociales, género. 
A violência contra a mulher é uma prática naturalizada em nossa sociedade. No Brasil, 4.762 assassinatos de mulheres foram registrados em 2013; destes 50,3\% foram cometidos por familiares, sendo que em $33,2 \%$ destes casos o crime foi praticado pelo atual ou ex-companheiro da vítima (Waiselfisz, 2015). Por se tratar de uma violência naturalizada, as mulheres têm dificuldade em nomear em suas relações situações de abuso e violência, podendo passar anos em situação de vulnerabilidade. Quando conseguem procurar ajuda, muitas vezes não recebem atendimento adequado, sendo culpabilizadas e silenciadas. Para tentar mudar a realidade dessa violência no Brasil, cada vez mais propostas vêm surgindo, dentre elas a Lei Maria da Penha, delegacias especializadas no atendimento às mulheres vítimas de violência, redes de enfrentamento à violência contra a mulher e propostas regionalizadas, como o Núcleo Maria da Penha (NUMAPE), projeto de extensão financiado pela Secretaria Da Ciência, Tecnologia e Ensino Superior do Estado do Paraná, que se propõe a prestar auxílio jurídico e psicológico às mulheres, bem como a promover a prevenção da violência por meio da conscientização da população, e em especial das mulheres, acerca da manifestação da violência de gênero, contribuindo para a divulgação e efetivação da Lei 11.340 de 2006, conhecida como Lei Maria da Penha (2006).

Atualmente, existem dez núcleos no estado do Paraná, sendo que um deles está localizado na cidade de Irati. Assim, este trabalho tem como objetivo apresentar o projeto de extensão NUMAPE, discutindo a proposta do núcleo de Irati, suas especificidades, possibilidades e limites no enfrentamento à violência contra a mulher, de acordo com o contexto em que está inserido.

Tendo isso em vista, a presente pesquisa justifica-se pela importância de propostas de enfrentamento à violência contra a mulher, já que se trata de uma temática amplamente discutida, que afeta diretamente a vida das mulheres e da sociedade como um todo. Os relatos de experiências como essa são necessários com vistas a produzir conhecimento acerca do assunto em questão e a levá-lo para as discussões no meio acadêmico. Justifica-se, ainda, por não existirem estudos que abordem especificamente o NUMAPE, uma vez que se trata de um projeto recente sobre o qual discorreremos a seguir.

\section{Núcleo Maria da Penha-NUMAPE}

O NUMAPE é um projeto de extensão, vinculado ao Programa Universidade Sem Fronteiras, financiado pela Secretaria da Ciência, Tecnologia e Ensino Superior (SETI) do Estado do Paraná. Propõe-se a prestar apoio jurídico e de enfrentamento à violência contra a mulher, trabalhando em conjunto com instituições que abordam a temática da defesa dos direitos das mulheres, assim contribuindo para a divulgação e efetivação da Lei Maria da Penha (NUMAPE, s/d). Segundo a regulamentação do Programa Universidade Sem Fronteiras, trata-se de um projeto de cunho interdisciplinar, que procura articular ações das áreas do Direito, Psicologia, Serviço Social, Pedagogia e outras áreas afins.

O projeto de extensão NUMAPE teve origem em 2013, em Londrina, no Paraná, sob coordenação da professora do curso de Direito Claudete Carvalho Canezin, propondo-se a prestar atendimento jurídico e psicológico às mulheres de baixa renda que residem em Londrina, que têm o interesse no processo de divórcio ou dissolução de união estável, bem como na regularização de visitas e guarda dos filhos, alimentos e partilha de bens decorrentes da separação. Outro eixo diz respeito à conscientização, esclarecendo às mulheres sobre os tipos de violência existentes (física, verbal, psicológica, moral e patrimonial) (NUMAPE, s/d).

O NUMAPE do município de Irati, vinculado à Universidade Estadual do Centro-Oeste UNICENTRO, no Paraná, teve início em abril de 2017, sendo coordenado por uma das autoras deste artigo, professora do curso de Psicologia. Diferentemente do projeto pioneiro, a proposta 
do NUMAPE/Irati não possui, em seu primeiro ano de atuação, a prestação de serviços jurídicos, já que a Universidade Estadual do Centro-Oeste não conta com o curso de Direito. O NUMAPE/Irati volta seu trabalho para o atendimento psicológico às mulheres em situação de violência, bem como orientação e acompanhamento das mulheres em casos em que se faz necessária a realização de boletins de ocorrência e outros encaminhamentos, de acordo com a especificidade de cada caso. Tratase de um projeto que organiza suas ações baseado na interconexão dos saberes de uma equipe interdisciplinar - composta por orientadoras, profissionais e estagiárias da Psicologia e Pedagogia -, e trabalha com o eixo preventivo, entendendo a importância da disseminação de informações e divulgação da Lei Maria da Penha, bem como da realização de atividades educativas e de conscientização da sociedade como um todo no que se refere às relações de gênero. O NUMAPE ainda trabalha no fortalecimento da Rede de Enfrentamento à Violência Contra as Mulheres, que será melhor descrita a seguir.

\section{Rede de enfrentamento à violência contra a mulher}

Rede pode ser entendida como um conjunto articulado de ações e serviços de saúde com vistas à assistência integral (Brasil, 2010). A noção de rede surge no Brasil a partir da organização do Sistema Único de Saúde (SUS), com base na Lei 80/80, de 1990, funcionando nas três esferas, nacional, estadual e municipal. A esfera municipal possibilita a maior autonomia de cada município em relação à gestão de recursos e estratégias de ação de acordo com a especificidade de cada um. Desta forma, algumas estratégias de ação são necessárias para a efetivação do que o SUS propõe enquanto lei, como as Redes de Atenção em Saúde (RAS), que são organizações de diferentes serviços cujo objetivo é trabalhar em conjunto para oferecer atendimento contínuo e integral para determinada população (Brasil, 2010).

Emprestando essa noção de rede, em relação ao atendimento específico para as mulheres, segundo a cartilha da Secretaria de Políticas Públicas para as Mulheres (Brasil, 2011), foram construídas as redes de enfrentamento à violência contra as Mulheres e rede de atendimento às mulheres em situação de violência. As primeiras são organizações amplas que pautam suas ações nos eixos de combate, prevenção, assistência e garantia dos direitos das mulheres, sendo caracterizadas como ações articuladas entre instituições governamentais, não governamentais e a sociedade. Tais ações visam à efetivação desses direitos, buscando desenvolver estratégias efetivas de prevenção, enfrentamento da violência e assistência integral às mulheres em situação de violência, bem como responsabilização dos agressores.

As redes de atendimento às mulheres, que fazem parte das redes de enfrentamento à violência, caracterizam-se como "conjunto de ações e serviços de diferentes setores (em especial, da assistência social, da justiça, da segurança pública e da saúde)" (Brasil, 2011, p. 8) que têm como objetivo, através do eixo da assistência, efetivar o direito das mulheres em situação de violência em ter um atendimento integral e humanizado, bem como realizar os encaminhamentos necessários para os órgãos competentes de acordo com a especificidade e complexidade de cada caso.

Em Irati, não existe uma rede de enfrentamento à violência contra a mulher em funcionamento, tendo em vista que a estruturação de uma rede ideal contaria com a oferta de serviços como centros de atendimento à mulher em situação de violência (centros de referência de atendimento à mulher, núcleos de atendimento à mulher em situação de violência, centros integrados da mulher), casas-abrigo, casas de acolhimento provisório (casas de passagem), delegacias especializadas de atendimento à mulher-DEAMs (postos ou seções da Polícia de Atendimento à Mulher), núcleos da mulher nas defensorias públicas, núcleos de gênero nos Ministérios Públicos, promotorias 
especializadas, juizados especiais de violência doméstica e familiar contra a mulher, Central de Atendimento à Mulher - Ligue 180, serviços de saúde voltados para o atendimento aos casos de violência sexual e doméstica, Instituto Médico Legal (IML), dentre outros serviços (Brasil, 2011).

Os casos de violência em Irati são acompanhados pelos Centros de Referência de Assistência Social (CRAS) e pelo Centro de Referência Especializado de Assistência Social (CREAS) do município. O acolhimento para mulheres vítimas de violência é realizado através da Casa de Apoio à Mulher Vítima de Violência, um espaço provisório e emergencial para mulheres e seus filhos, com capacidade para acolher até oito pessoas (entre mulheres e crianças), quando se faz necessário o afastamento da mulher da sua residência e se esgotam os recursos financeiros e familiares (Irati, 2015). Para o registro de denúncias, os casos são encaminhados para a delegacia comum da cidade, visto que não existe uma delegacia especializada no atendimento de mulheres em situação de violência.

Nos anos de 2016 e 2017, têm sido efetuadas discussões no sentido de estabelecer esta rede de enfrentamento à violência contra a mulher em Irati; no entanto, algumas questões, como mudanças de gestão do município, acabam por inviabilizar seu funcionamento. Atualmente, está em processo de formação o Conselho da Mulher, órgão responsável por mapear e fiscalizar os equipamentos e ações no município relacionadas à mulher. Fazem parte desse conselho representantes de grupos de mulheres e também dos serviços vinculados à Rede de Prevenção e Enfrentamento às Violências; seus membros são profissionais da Secretaria Municipal de Assistência Social, Saúde, Educação, Segurança Pública, entre outros setores do município.

$\mathrm{O}$ não estabelecimento dessa rede e as dificuldades decorrentes da falta de estrutura mínima de atendimento à mulher em situação de violência fazem com que não seja possível realizar o levantamento dos casos de violência contra a mulher no município. Foi estabelecido como diretriz nacional, com a publicação da Portaria $\mathrm{n}^{\mathrm{o}} 104$, de 25 de janeiro de 2011, e posteriormente da Portaria $n^{\circ} 1.271$, de 06 de junho de 2014, do Ministério da Saúde, a utilização da Ficha do Sistema de Informação de Agravos de Notificação (SINAN) para notificação individual, compulsória, de qualquer caso suspeito ou confirmado de violência doméstica/intrafamiliar (Brasil, 2015). Desta forma, se torna possível mapear e registrar os casos de violência no município; tal uso, entretanto, não foi efetivado, uma vez que existem casos em que não ocorre a notificação, ou ainda a subnotificação, já que nem todos os casos são registrados no sistema. A notificação dos casos de violência contra a mulher, através da ficha do SINAN, caracteriza-se como um importante instrumento de registro por possibilitar o mapeamento da ocorrência destas violências no município, contribuindo para produzir dados epidemiológicos dessa população; além disso, pode fornecer embasamento para o planejamento de políticas públicas e a definição de prioridades de intervenção, permitindo ainda, a posteriori, a avaliação do impacto dessas intervenções (Brasil, 2016).

Considerando as configurações da Rede de Atendimento à Mulher em situação de violência no município, é possível entender a importância de um projeto de extensão voltado para o atendimento dessa população, uma vez que os demais serviços da rede de assistência social recebem uma demanda bastante grande de atendimentos do público em geral, não sendo possível priorizar os atendimentos voltados às mulheres de forma exclusiva.

Desta forma, o NUMAPE funciona em parceria com a Secretaria Municipal de Assistência Social de Irati, buscando a articulação com os demais serviços da rede na realização do acolhimento das demandas relacionadas à violência contra a mulher e encaminhamento para os setores necessários. Estando ainda no início de sua implantação, o núcleo está organizando seus serviços e encontrando seu lugar na relação com os equipamentos existentes de atendimento às mulheres em situação de violência. 


\section{Desafios e limitações de um projeto de atendimento a mulheres em situação de violência}

Irati é um município do interior do Paraná, onde mais de $84 \%$ da população se denomina praticante da religião católica (IBGE, 2010); grande parte da população é de origem polonesa, ucraniana e holandesa (Paraná, s/d; Souza, 2009), caracterizada por manter costumes tradicionais (Lucavei \& Schörner, 2013), geralmente ancorados na religião. Ao retomar a história das mulheres, é possivel perceber que discursos religiosos, em sua maioria, reafirmam o papel da mulher enquanto inferior ao homem e, portanto, submissas a estes (Alves \& Pitanguy, 1985). Desse modo, por se tratar de um município que tem como característica a presença de discursos religiosos e conservadores, os papéis de gênero são bastante demarcados, e a violência contra a mulher é muitas vezes naturalizada.

Por não existir uma Rede de Enfrentamento à Violência contra a Mulher nem uma delegacia especializada no atendimento às mulheres, os profissionais muitas vezes não têm formação nem instrumentos adequados para atender à especificidade de violência de gênero. Assim, as mulheres em situação de violência não sabem onde procurar ajuda; e, quando procuram algum equipamento de serviço público, muitas vezes acabam sofrendo com a revitimização (Brasil, 2011), ou seja, não recebem o atendimento adequado, sendo obrigadas a contar suas histórias de violência diversas vezes e podem, inclusive, ser culpabilizadas por estarem nessa condição. Em alguns casos, encontram dificuldades para realizar procedimentos básicos, como o boletim de ocorrência ou efetivação de exame de corpo de delito. Situações como essas demonstram a importância de acompanhar as mulheres na realização dos encaminhamentos necessários, bem como de oferecer suporte nesses momentos em que se encontram em situação de profunda vulnerabilidade, visando garantir que os direitos da mulher sejam respeitados, e evitar que passem por situações de revitimização.
Desta forma, são necessárias discussões sobre a importância da criação e fortalecimento de uma rede de enfrentamento à violência contra a mulher, bem como a permanente formação dos profissionais que atuam dos serviços públicos do município, uma vez que os casos de violência são alarmantes. O fato de não haver ainda Defensoria Pública especializada no atendimento às mulheres em situação de violência demonstra a necessidade de auxílio jurídico especializado, uma vez que a maioria das mulheres não tem clareza dos trâmites que passam nas instâncias judiciais de apoio e nos setores de segurança pública, como a diferença entre o registro de um boletim de ocorrência e a representação, instauração de inquérito policial, nem tem clareza para que servem as medidas protetivas e quando devem ser solicitadas e aplicadas.

Outro eixo considerado fundamental, e que se encaixaria na Rede de Enfrentamento à Violência, é o preventivo. No NUMAPE de Irati, as ações estão relacionadas ao desenvolvimento de estratégias que visam informar a população sobre a temática da violência de gênero e sobre seus direitos, assim contribuindo para a efetivação da Lei Maria da Penha e da Política Nacional de Enfrentamento à Violência contra a Mulher. Ainda nesse eixo, algumas atividades que têm sido desenvolvidas estão relacionadas às discussões acerca das questões de gênero nos mais diferentes ambientes, como escolas, eventos na universidade, entre outros eventos no município.

Essas ações estão pautadas na compreensão de que as relações de gênero estão na base da produção da violência. Sobre isso, é possível afirmar que as diferenças entre os gêneros são construções sociais de relações distintas baseadas no sexo. Além disso, se organizam a partir de um discurso que apregoa o determinismo biológico que coloca como naturais características e papéis a serem desempenhados por homens e mulheres (Giffin, 1994). 
O Brasil ocupa o $5^{\circ}$ lugar no ranking de notificações de homicídios de mulheres em um grupo de 83 países (Waiselfisz, 2015). Em 2013, em uma média de 100 mil casos de homicídios femininos no Brasil, o Paraná registrou uma taxa de 5,2 \% dos casos. Em relação ao local de ocorrência de homicídio e violências, a residência se coloca como o local com maiores índices, sendo homicídios de mulheres em $27,1 \%$ dos casos, e outros tipos de violência 71, 9\% (Waiselfisz, 2015). Em relação à ficha do Sistema de Informação de Agravos de Notificação (SINAN), $65 \%$ das notificações realizadas SUS referem-se às mulheres. A cada três pessoas atendidas nos equipamentos de saúde em razão da violência, duas são mulheres, justificando-se, portanto, por que a violência de gênero é considerada um problema de saúde pública (Waiselfisz, 2011).

Em 2014, segundo dados oriundos do Mapa da Violência (2015), foram atendidas um total de 85,9 mil meninas e mulheres vítimas de violência, tendo como autores pais, parceiros e ex-parceiros, filhos, irmãos. É importante ressaltar que tais agressões apresentaram um nível de gravidade a ponto de demandarem atendimento médico. Partindo disso, é possível afirmar que as violências contra a mulher são violências baseadas em gênero, buscando a manutenção da dominação masculina sobre as mulheres (Ritt, Cagliari \& Costa, s/d). A manutenção dessa lógica pode ser comprovada uma vez que os casos de violência se dão na relação com homens próximos, o que configura o caráter doméstico. Esses e outros dados e características da violência contra a mulher justificam a importância da atuação do NUMAPE, bem como de outros equipamentos do município de Irati na atuação voltada para o eixo preventivo.

Pensando nas ações do projeto de um modo geral, é possível elencar alguns alcances e limites que se têm colocado durante seu tempo de funcionamento. O núcleo oferece espaço de escuta e discussão sobre a questão da violência contra a mulher, bem como serviços de atendimento psicológico e acompanhamento de mulheres em processos de enfrentamento a situações de violência. No entanto, em seu percurso, por se tratar de um projeto de extensão, encontra alguns limites como, por exemplo, a definição do seu papel, a falta de auxílio jurídico em um espaço em que as demandas materializam essa necessidade, a dificuldade de inserção na rede de atendimento às situações de violência, bem como a dificuldade de articulação entre os equipamentos em uma rede que se encontra em processo de construção.

Um primeiro eixo de trabalho do NUMAPE tem sido o atendimento psicológico individual e/ou em grupo para mulheres em situação de violência. Embora seja um serviço que consideramos extremamente necessário para o enfrentamento desse tipo de situação, há dificuldades nos processos de encaminhamento de outros órgãos para o projeto, e ainda dificuldades de ordem prática, como a localização do núcleo, que fica em um campus universitário, afastado do centro da cidade. Entretanto, algumas parcerias têm funcionado no encaminhamento para atendimentos. Destacamos o fluxo estabelecido com o Núcleo de Estudos de Defesa dos Direitos da Infância e da JuventudeNEDDJI, outro projeto coordenado por docente do curso de Psicologia da mesma universidade. Como os casos atendidos de violação de direitos de crianças e adolescentes geralmente estão relacionados a histórico de violência familiar, e como esse histórico afeta diretamente a vida desses sujeitos, são feitos encaminhamentos regulares aos órgãos competentes e há um trabalho em conjunto entre NUMAPE e NEDDJI. Outra parceria recentemente estabelecida, a partir de proposta da Vara Criminal do município em atuar pelos princípios da justiça restaurativa, é com o programa Patronato (substituto do programa Pró-Egresso), cujo objetivo é a reinserção social de egressos do sistema carcerário beneficiados com a progressão para o regime aberto. Nesta proposta, os casos relacionados à Lei Maria da Penha são encaminhados para atendimento no Patronato, e as mulheres que desejarem acompanhamento psicológico são encaminhadas ao NUMAPE. Ambos os projetos têm discutido ações que possam, com base em casos já judicializados, promover o enfrentamento das situações de violência e a prevenção da reincidência. 
Além dos atendimentos psicológicos descritos anteriormente, uma ação inicialmente não prevista pelo NUMAPE - mas que se mostrou necessária justamente em função da não existência de órgãos competentes, com especialização e formação para o atendimento a casos de violência contra a mulher - é o acompanhamento das mulheres durante o processo de denúncia e encaminhamento para esses órgãos. Os casos atendidos permitiram que se percebecesse um aspecto já discutido recorrentemente na literatura (Lattiere \& Nakano, 2011): a dificuldade de as mulheres darem prosseguimento ao processo de denúncia, mesmo quando há o rompimento da relação, já que as mulheres não se sentem seguras nem assistidas pelos serviços que lhes deveriam prestar acolhimento. Nesse sentido, um dos eixos de atendimento foi justamente o acompanhamento das mulheres que procuravam o núcleo nos mais diversos locais, tais como durante o registro do boletim de ocorrência, nos serviços de saúde e de assistência social, etc., como forma de garantir que os direitos dessas mulheres fossem minimamente respeitados e também que pudessem ter suporte durante esses momentos em que muitas vezes não recebiam da rede de apoio. Obviamente tal acompanhamento só se deu quando as mulheres manifestaram esse desejo, o que ocorreu na maioria das vezes, já que pareciam se sentir mais seguras com um profissional ao seu lado, ainda que esse "profissional" (que muitas vezes são as estagiárias do projeto) não pertenciam à área do Direito.

Em que pese a tentativa de responder às demandas que nos são dirigidas, dada a fragilidade da Rede de Atendimento à Mulher no município em que nos inserimos, não podemos perder de vista, entretanto, que projetos como o NUMAPE têm ocupado um lugar na rede que vai além das suas atribuições enquanto um projeto de extensão, suprindo necessidades de equipamentos e serviços que não são oferecidos. Essa questão se apresenta aos membros do projeto enquanto um dilema ético: prestar atendimento e ocupar o lugar de um serviço faltante na rede de atendimento, ou deixar de atender a uma demanda para a qual não existe serviço especializado? Temos procurado estabelecer um ponto de equilíbrio, atendendo aos casos que nos procuram, mas procurando sobretudo atuar no auxílio da organização de uma rede de atendimento que melhor dê conta das necessidades do município. Algumas ações nesse sentido têm se dado a partir da atuação em conselhos e instâncias municipais que se voltam à discussão sobre as mulheres em situação de violência; proposição de formações, cursos, palestras, voltadas aos equipamentos da Rede; também são organizadas ações a partir de um eixo preventivo, como trabalhos em escolas, instituições, eventos e a proposição de campanhas, procurando dar visibilidade à questão da violência contra a mulher e às formas de prevenção.

Por fim, uma demanda que tem sido endereçada ao NUMAPE - uma vez que esse núcleo funciona em um espaço que se localiza na universidade e faz uso de recursos humanos também oriundos dessa instituição - é a problematização por parte de seus agentes acerca das manifestações de violência que ocorrem dentro no próprio espaço universitário. Relatos e denúncias de assédio entre alunos, professores e funcionários rondam os corredores e são pautas correntes, mas não chegam a se tornar oficiais. Nesse sentido, têm sido realizados alguns atendimentos com acadêmicas e têm sido propostos espaços de debate.

Atualmente, os casos de violência dentro da universidade em que há interesse de denunciar formalmente o agressor precisam cumprir os trâmites jurídicos e formais próprios da lógica institucional, por meio de protocolos de sindicância instaurados pela universidade para a formalização e apuração das denúncias. Para tanto, é necessário identificar o autor da agressão; e, durante a tramitação do processo, a depoente pode ser chamada para relatar novamente a violência sofrida, o que abre margem para a revitimização. Além disso, as denunciantes sentem-se inseguras por ter seu nome identificado, o que demonstra a necessidade de estabelecer protocolos diferenciados, ou seja, que não envolvam processos burocráticos que promovam a exposição daquelas que denunciam, 
já que esse procedimento inviabiliza na maioria das vezes as denúncias por medo de retaliação. Soma-se a isso a morosidade do processo e a necessidade de a vítima continuar partilhando de espaços e se relacionando com o autor da agressão (frequentando aulas ou serviços, sendo avaliadas, entre outros tipos de relações). Destacase ainda que as denúncias de abuso ocorrido na universidade são julgadas inicialmente no âmbito dos próprios setores responsáveis (departamentos pedagógicos ou setores administrativos), entre colegas muitas vezes dos autores e/ou das vítimas. Em situações como essas, perpassam relações de poder instituídas que se colocam como determinantes no processo de produção e manutenção das violências (Almeida, 2017).

Sabemos que tais condições não são diferentes em outros contextos universitários. A pesquisa Violência contra a mulher no ambiente universitário (2015), realizada nas cinco regiões do Brasil, afirma que $67 \%$ das mulheres já sofreram algum tipo de violência (sexual, psicológica, moral ou física) nesse ambiente; $56 \%$ sofreram assédio sexual; 52\% relataram situações de agressão moral ou psicológica; $49 \%$ já foram desqualificadas intelectualmente; $42 \%$ afirmaram ter medo de passar por situações de violência; $28 \%$ já passaram por situações diversas de violência sexual, como estupro, tentativa de abuso, e já tiveram seus corpos tocados sem consentimento e/ou foram forçadas a beijar algum aluno veterano; $18 \%$ sofreram coerção; e 10\% relataram ter passado por alguma situação de violência física (Almeida, 2017).

Um aspecto a ser destacado nessa pesquisa realizada acerca da violência no espaço universitário é que os perpetradores não conseguem perceber como violência as suas ações -apenas $2 \%$ admitiram ter cometido algum ato de violência. Entretanto, após a apresentação de uma lista de situações violentas, esse percentual aumentou para $38 \%$. Destacam-se algumas afirmações:

Para $27 \%$ deles, não é violência abusar sexualmente de uma garota alcoolizada; para 35\% deles, não há violência no ato de coagiruma mulher a participar de atividades degradantes, por exemplo, nos trotes e em rankings sexuais; $e$ $31 \%$ deles não veem problema em repassar fotos ou vídeos das colegas sem autorização delas. Apenas 38\% deles admitiram já ter realizado algum tipo de violência contra mulheres em espaços acadêmicos (Almeida, 2017, p. 388).

A tais resultados é acrescentada a afirmação de que as ações desempenhadas cotidianamente por homens nos espaços e entornos universitários não são violências, mas resultantes dos próprios comportamentos das mulheres e/ou brincadeiras inofensivas; e, portanto, não deveriam ter o caráter de exposição e denúncia promovido pelas acadêmicas e principalmente pelos coletivos feministas. A naturalização dessa discriminação com a condição feminina faz com que, muitas vezes, violências relacionadas ao gênero não sejam reconhecidas e nomeadas nem por quem as pratica, nem por quem as sofre. A perpetuação de agressões reiteradas contra mulheres dificulta qualquer tipo de tratamento adequado para esses casos, bem como a prevenção. (Almeida, 2017).

Diante do contexto de naturalização das violências no cotidiano acadêmico, coletivos feministas e núcleos de pesquisa sobre gênero e outros marcadores sociais (raça, classe, etc.) têm se colocado como protagonistas na luta pelo reconhecimento das formas de violência dentro das universidades, por meio de diferentes estratégias de denúncia, prevenção e enfrentamento das violências (Almeida, 2017). Um exemplo é a proposta do Centro de Referência de Atendimento à Mulher e às Vítimas de Violência de Gênero, que surgiu de uma demanda de alunas da Universidade de São Paulo (USP) com o objetivo de garantir suporte jurídico, psicossocial e de saúde física às mulheres (USP, 2017).

Diante dessa problemática e dos altos índices de violência relatados pelas mulheres dentro das universidades, em todo o Brasil se faz necessária uma discussão mais ampla acerca da realidade das mulheres inseridas nesses espaços, bem como a promoção de maior conscientização no ambiente acadêmico, buscando o compromisso e 
responsabilização das instituições pela criação de políticas efetivas de enfrentamento da violência institucionalizada, bem como a garantia de condições de inserção e permanência das mulheres dentro da universidade; "afinal, a universidade deveria ser um espaço de liberdade e de consciência crítica à reprodução de todas as formas de poder" (Almeida, 2017. p. 391).

As ações no NUMAPE, nesse aspecto, iniciaram com a criação de formas de levantamento de dados de casos de violência e assédio no ambiente universitário, com vistas a retirar essa questão da invisibilidade. A discussão desses dados, ainda informais, tornou-se pública em um evento de lançamento do projeto na instituição em que nos situamos- Universidade Estadual do CentroOeste-UNICENTRO-, e vem avançando com a proposição de espaços e comissões que possam avaliar, julgar e coibir situações de violência, sobretudo as relacionadas a questões de gênero na universidade.

\section{Considerações Finais}

Este trabalho teve como objetivo apresentar as ações desenvolvidas pelo NUMAPE da Universidade Estadual do Centro-Oeste, do Paraná. Como afirmamos anteriormente, o projeto tem trabalhado a partir dos eixos preventivo e curativo. No primeiro eixo, as ações têm se voltado à proposição de campanhas de conscientização e informação acerca da violência, da discussão de como as mais diferentes formas de violências estão assentadas em relações de gênero, dos tipos de violência preconizados pela Lei Maria da Penha, etc. Outras ações fundamentais, nesse sentido, têm sido a participação em encontros da Rede Municipal de Enfrentamento à Violência, do Conselho da Mulher e a proposição de capacitação para os setores que atuam na Rede de Atendimento à Violência contra a Mulher. No eixo curativo, temos realizado atendimento psicológico às mulheres - que nos procuram espontaneamente ou são encaminhadas por outros serviços -, efetivado acompanhamento, e prestado informações às mulheres durante o processo de denúncia e enfrentamento das situações de violência.

Os limites de nossa atuação esbarram na definição do papel do NUMAPE na Rede de Atendimento; na necessidade de implantação do auxílio jurídico (que ocorrerá no ano de 2018); na dificuldade de articulação entre os equipamentos em uma rede que se encontra em processo de formação; e sobretudo na dificuldade de colocar em pauta a desnaturalização da violência contra a mulher em um contexto extremamente conservador, que ainda mantém relações de gênero extremamente desiguais. Outro aspecto inquietante diz respeito ao dilema ético, já mencionado, que coloca em questão as demandas que pouco a pouco nos são apresentadas, e o quanto o atendimento a essas demandas pode produzir um efeito de "maquiagem" da falta de serviços básicos de atendimento à mulher em situação de violência no município. Nesse aspecto, temos buscado o equilíbrio entre nossas práticas, denunciando a carência desses serviços por meio da participação em conselhos e instâncias municipais que se voltam à discussão das mulheres em situação de violência, e também propondo formações, cursos, palestras voltadas aos equipamentos da rede, a fim de melhorar a qualidade do serviço prestado pelos equipamentos de que dispomos.

Por fim, ainda que não fosse o objetivo inicial do projeto, ações preventivas e curativas têm sido solicitadas no próprio contexto universitário. Assim, temos realizado atendimento de alguns casos e proposto discussões acerca das questões de violência que ocorrem dentro desse espaço. Relatos e denúncias de assédio entre alunos, professores e funcionários tem sido objeto de reflexão; e, juntamente com outros setores, temos pensado em formas de encaminhamento. Afinal, ignorar que violências contra as mulheres ocorrem o tempo todo, inclusive no espaço universitário, seria colocar-se de maneira incoerente aos pressupostos do projeto. 


\section{Referências}

Almeida, T. M.C. (2017). Violências contra mulheres nos espaços universitários. In C. Stevens, S. Oliveira, V. Zanello, E Silva, \& C. Portela (Orgs.), Mulheres e violências: Interseccionalidades. (pp. 384-399). Brasília: Technopolitik

Alves, B. M., \& Pitanguy, J. (1985). O que é feminismo. São Paulo: Abril Cultural/ Brasiliense.

Brasil. Ministério da Saúde. (2016). Sistema Nacional de Agravos de Notificação (SINAN). Recuperado de <http:// renastonline.ensp.fiocruz.br/temas/sistema-nacionalagravos-notificacao-sinan>

Brasil. Ministério da Saúde. (2010). Recuperado de <http:// dab.saude.gov.br/portaldab/smp_ras.php>

Brasil. Ministério da saúde. (2015). Instrutivo notificação de violência interpessoal e autoprovocada. Recuperado de <http://portalarquivos.saude.gov.br/images/pdf/2016/ fevereiro/16/instrutivo-ficha-sinan-5-1--vers--ofinal-15-01-2016.pdf>

Brasil. (2011). Política Nacional de enfrentamento à violência contra as mulheres. Secretaria Especial de Políticas para mulheres. (pp. 7-44). Recuperado de: <http:// www.spm.gov.br/central-de-conteudos/publicacoes/ publicacoes/2011/politica-nacional>

Giffin, K. (1994). Violência de gênero, sexualidade e saúde. Cadernos de Saúde Pública, 10 (Supl. 1), p. 146-155. doi: 10.1590/S0102-311X1994000500010

IBGE- Instituto Brasileiro de Geografia e estatística. (2010). Recuperado de <https://cidades.ibge.gov.br/v4/brasil/ $\mathrm{pr} /$ irati/panorama>

Irati (PR). (2015). Guia de serviços, programas e projetos municipais. Irati, Secretaria Municipal de Assistência Social.

Paraná. (s/d). Etnias. Secretaria de Estado do Turismo SETU. Recuperado de <http://www.cidadao.pr.gov.br/ modules/conteudo/conteudo.php?conteudo $=77>$

Lei n. 11.340, de 7 de agosto de 2006. (2006). Lei Maria da Penha. Coíbe a violência doméstica e familiar contra a mulher. Brasília, DF: Presidência da República. Recuperado de <http://www.planalto.gov.br/ccivil_03/_ ato2004-2006/2006/lei/111340.htm>

Lettiere, A., \& Nakano, A. M. S. (2011) Violência doméstica: As possibilidades e os limites de enfrentamento. Recuperado de 〈http://www.scielo.br/pdf/rlae/v19n6/pt_20.pdf>

Lucavei, L., \& Schorner, A. (2013). Os rituais de casamento ucraniano entre permanências e transformações? Irati/ PR (1978-2008). Revista Tempo, Espaço e Linguagem, 4(1), 49-63. Recuperado de <http://www.revistas2.uepg.br/ index.php/tel/article/viewFile/4202/4000>

Ritt, C. F, Cagliari, C. T. S., \& Costa, C. M. Violência cometida contra a mulher compreendida como violência de gênero. Recuperado de <http://www.ufrgs.br/nucleomulher/ arquivos/artigo_violencide\%20genero>

Sousa, J. M. (2009). Imigrantes no Paraná: A inserção e contribuição poloneza em Irati/Pr. I seminário nacional sociologia e política UFPR. Recuperado de <http://www. humanas.ufpr.br/site/evento/SociologiaPolitica/GTsONLINE/GT4/EixoI/imigrantes-parana-JoabSousa.pdf>

Universidade Estadual de Londrina. NUMAPE. s/d Recuperado de <http://www.uel.br/nucleos/numape/ pages/historico-e-objetivos-do-projeto.php>

Universidade de São Paulo. (2017). USP terá Centro de Referência para Mulheres. Jornal do Campus. Recuperado de <http://www.jornaldocampus.usp.br/index. php/2017/09/usp-tera-centro-de-referencia-paramulheres/>

Waiselfisz, J. J. (2011). Mapa da Violência 2012. Os novos padrões da violência homicida no Brasil. São Paulo, Instituto Sangari. Recuperado de <http:// mapadaviolencia.org.br/pdf2012/mapa2012_web.pdf>

Waiselfisz, J. J. (2015). Mapa da violência 2015. Homicídio de Mulheres no Brasil. Brasília, 8-74. Recuperado de <http://www.mapadaviolencia.org.br/pdf2016/ Mapa2016_armas_web.pdf $>$ 